\title{
OPEN Effects of danofloxacin dosing regimen on gastrointestinal pharmacokinetics and fecal microbiome in steers
}

\author{
J. L. Halleran ${ }^{1 凶}$, B. J. Callahan ${ }^{1}$, M. E. Jacob ${ }^{1}$, H. J. Sylvester ${ }^{1}$, T. Prange², M. G. Papich ${ }^{3}$ \& \\ D. M. Foster ${ }^{1}$
}

Fluoroquinolones are a class of antimicrobial commonly used in human medicine, and deemed critical by the World Health Organization. Nonetheless, two formulations are approved for the treatment of respiratory disease in beef cattle. The objective of this study was to determine the gastrointestinal pharmacokinetics and impact on enteric bacteria of cattle when receiving one of the two dosing regimens (high: $40 \mathrm{mg} / \mathrm{kg}$ SC once or low: $20 \mathrm{mg} / \mathrm{kg}$ IM q48hr) of danofloxacin, a commonly utilized synthetic fluoroquinolone in veterinary medicine. Danofloxacin was administered to 12 steers (age 7 months) fitted with intestinal ultrafiltration devices at two different dosing regimens to assess the gastrointestinal pharmacokinetics, the shifts in the gastrointestinal microbiome and the development of resistant bacterial isolates. Our results demonstrated high intestinal penetration of danofloxacin for both dosing groups, as well as, significant differences in MIC values for $E$. coli and Enterococcus between dosing groups at selected time points over a 38 day period. Danofloxacin treatment consistently resulted in the Euryarchaeota phyla decreasing over time, specifically due to a decrease in Methanobrevibacter. Although microbiome differences were minor between dosing groups, the low dose group had a higher number of isolates with MIC values high enough to cause clinically relevant resistance. This information would help guide veterinarians as to appropriate dosing schemes to minimize the spread of antimicrobial resistance.

Fluoroquinolones are considered a critically important antibiotic in human medicine ${ }^{1,2}$. Therefore, in the United States and European Union, the use of fluoroquinolones in veterinary medicine is restricted to on label usage as there are concerns that increased use can lead to an increased risk of antimicrobial resistance (AMR) in both veterinary and human patients ${ }^{3,4}$. Fluoroquinolone bacterial resistance is associated with three recognized mechanisms: mutations that alter the target of the drug, mutations that will reduce drug accumulation, and the presence of plasmids that encode genes that protect the cell ${ }^{5,6}$. Genes associated with fluoroquinolone resistance have been documented in cattle feces through metagenomics studies, demonstrating that feces could be a source of AMR transmission to water or $\mathrm{crops}^{7-9}$. Dosing regimen has been found to play a role in the development and acquisition of AMR in bacteria. "Inadequate exposure" of a therapeutic occurs when a sub-therapeutic administration of an antibiotic is given, resulting in inefficient killing of bacteria with borderline susceptibility ${ }^{10}$. These borderline bacteria will survive, leading to an antibiotic resistant population. Therefore, dosing regimens should be designed to achieve adequate therapeutic drug concentrations early in treatment to eliminate the borderline susceptible group of bacteria in order to decrease risk of resistant populations.

Danofloxacin, a synthetic fluoroquinolone, is a commonly used veterinary antimicrobial currently labeled for treatment and control of bovine respiratory disease associated with Mannheimia haemolytica and Pasteurella multocidia in beef cattle ${ }^{1}$. Like other fluoroqinolones, danofloxacin acts by inhibiting bacterial DNA gyrase, preventing DNA replication, causing it to be bactericidial. Danofloxacin's veterinary label has two dosing regimens, a lower multi-day therapy and higher single dose therapy. The withdrawal time required prior to an animal entering the food chain after treatment with either regimen is 4 days after the last dose. This short withdrawal

${ }^{1}$ Department of Population Health and Pathobiology, College of Veterinary Medicine, NC State University, Raleigh, NC, USA. ${ }^{2}$ Department of Clinical Sciences, College of Veterinary Medicine, NC State University, Raleigh, NC, USA. ${ }^{3}$ Deparment of Biomedical Sciences, College of Veterinary Medicine, NC State University, Raleigh, NC, USA. ${ }^{\circledR}$ email: jlhaller@ncsu.edu 


\begin{tabular}{|c|c|c|c|c|c|}
\hline \multirow[b]{2}{*}{ Parameter } & \multirow[b]{2}{*}{ Units } & \multicolumn{2}{|l|}{$6 \mathrm{mg} / \mathrm{kg}$} & \multicolumn{2}{|l|}{$8 \mathrm{mg} / \mathrm{kg}$} \\
\hline & & Geometric mean & Geometric CV \% & Geometric mean & Geometric CV \% \\
\hline A & $\mathrm{ug} / \mathrm{ml}$ & 1.938 & 27.790 & 2.847 & 25.566 \\
\hline Alpha & $1 / \mathrm{h}$ & 0.181 & 12.073 & 0.167 & 18.365 \\
\hline Alpha $t^{1} / 2$ & $\mathrm{~h}$ & 3.833 & 11.996 & 4.154 & 18.389 \\
\hline AUC & $\mathrm{h} \mathrm{ug} / \mathrm{ml}$ & 13.647 & 27.970 & 19.179 & 16.258 \\
\hline B & $\mathrm{ug} / \mathrm{ml}$ & 0.125 & 67.867 & 0.167 & 45.863 \\
\hline Beta & $1 / \mathrm{h}$ & 0.043 & 37.142 & 0.046 & 94.110 \\
\hline Beta $t^{1 / 2}$ & $\mathrm{~h}$ & 17.587 & 52.043 & 15.015 & 92.243 \\
\hline CMAX & $\mathrm{ug} / \mathrm{ml}$ & 1.625 & 26.801 & 2.002 & 16.936 \\
\hline K01 & $1 / \mathrm{h}$ & 3.409 & 102.592 & 1.734 & 66.131 \\
\hline K01 t¹/2 & $\mathrm{h}$ & 0.204 & 102.389 & 0.400 & 66.157 \\
\hline TMAX & $\mathrm{h}$ & 0.910 & 67.713 & 1.479 & 39.938 \\
\hline
\end{tabular}

Table 1. Pharmacokinetic parameters for danofloxacin in plasma dosed at $6 \mathrm{mg} / \mathrm{kg}$ under the skin every $48 \mathrm{~h}$ for two doses and $8 \mathrm{mg} / \mathrm{kg}$ under the skin once. $\mathrm{A}, \mathrm{B}$, the intercept for the initial and terminal portions of the curve, respectively. Alpha $(\alpha)$ and beta $(\beta)$ are the rate constants for the initial and terminal portions of the curves, with their respective half-lives $\left(\mathrm{t}^{1} \frac{1}{2}\right) . \mathrm{K} 01$ is the absorption rate and corresponding half-life $\left(\mathrm{t}^{1} / 2\right) . C_{M A X}$ maximum drug concentration, $T_{M A X}$ time to maximum drug concentration.

time is beneficial to owners, but may allow for the persistence of resistant bacteria when the animal goes to slaughter. This antimicrobial is marketed for treatment of respiratory disease, yet administration of parenteral antibiotics can affect the composition and susceptibility of the gastrointestinal microbiota ${ }^{10-13}$. Understanding the gastrointestinal pharmacokinetic/pharmacodynamic relationship and how it correlates to minimum inhibitory concentrations (MICs) and microbiome changes can shed light on the development of AMR, providing guidance for clinical use of these drugs.

The overall objective of this study was to assess the pharmacodynamic properties associated with both dosing regimens of danofloxacin and the subsequent development of antimicrobial resistance in enteric bacteria.

We have a two-part hypothesis. First, steers administered the lower dose of danofloxacin twice will have lower gastrointestinal concentrations when compared to the steers whom received the single, high dose of danofloxacin. Second, the decreased gastrointestinal concentrations from the low dose group will allow for an increased development, amplification and persistence of a resistant sub-population of enteric bacteria. Briefly, this was carried out through dosing at time point 0 with sample collection of blood, intestinal ultrafiltrate and interstitial fluid at various time points over the first 7 days of the study. Feces was collected over 27 days, allowing for a longitudinal design to assess changes in antimicrobial resistance over time.

\section{Results}

Pharmacokinetic modeling. The values of the pharmacokinetic parameters for both dosing groups in all sample types are shown in Tables 1 and 2. The mean AUC for the low group was $14.08 \mathrm{~h} \mathrm{ug} / \mathrm{ml}$ and for the high dose group was $19.39 \mathrm{~h} \mathrm{ug} / \mathrm{ml}$. The mean plasma half-life was approximately $20 \mathrm{~h}$ from both doses (Figs. 1, 2 ). The half-life for interstitial fluid was also significantly different between dosing groups ( $\mathrm{p}$ value $<0.05$ ); it was higher in the low dose group. The maximum drug concentration was significantly different between the dosing groups in the ileum gastrointestinal ultrafiltrate ( $\mathrm{p}$ value $<0.05$ ); the maximum drug concentration was increased in the high dose group. All other parameters were not significantly different between dosing groups for plasma, interstitial fluid, ileum or colon ultrafiltrate. There was high intestinal penetration of approximately $700 \%$ or higher in the ileum and $500-600 \%$ in the colon following administration of both the high and low doses of danofloxacin (Tables 1, 2, 3, 4, Figs. 1,2).

Plasma protein binding. The plasma protein binding was $36.4 \%$ ( $0.37 \mathrm{Std}$.Dev) for the concentration of $1.0 \mu \mathrm{g} / \mathrm{ml}$, and $39.4 \%$ (0.31 standard deviation) for the concentration of $0.5 \mu \mathrm{g} / \mathrm{ml}$.

Concentration of $E$. coli and Enterococcus. Figure 3 shows the mean concentration $\left(\log _{10} \mathrm{CFU} / \mathrm{g}\right)$ over time per dosing group for both E. coli (3A) and Enterococcus (3B) respectively. The concentration of E. coli dropped substantially after administration of danofloxacin, but it recovered and returned to baseline over time. There was significant difference in $\log$ CFU/g of E. coli when comparing Day 6 (144 h) to Day 0 for the low dose group ( $\mathrm{p}=0.0006)$. There was no significant difference in $\log C F U / g$ of $E$. coli when comparing Day 0 to Day 4 $(96 \mathrm{~h})$ for the high dose group, or any difference between dosing groups at time point Day 4 and Day 6 . These times were specifically evaluated as this is the earliest that the animal could enter the food chain. After administration of danofloxacin, there was no substantial effect on the concentration of Enterococcus, with no significant differences observed in $\log \mathrm{CFU} / \mathrm{g}$ between days 0,4 and 6 .

E. coli and Enterococcus minimum inhibitory concentration. Descriptive statistics for MIC values for both E. coli and Enterococcus are shown in Supplementary Tables S1 and S2. 


\begin{tabular}{|c|c|c|c|c|c|}
\hline \multirow[b]{2}{*}{ Parameter } & \multirow[b]{2}{*}{ Units } & \multicolumn{2}{|l|}{$6 \mathrm{mg} / \mathrm{kg}$} & \multicolumn{2}{|l|}{$8 \mathrm{mg} / \mathrm{kg}$} \\
\hline & & Geometric mean & Geometric CV \% & Geometric mean & Geometric CV \% \\
\hline $\mathrm{A}$ & $\mathrm{ug} / \mathrm{ml}$ & 17.880 & 15.777 & 8.806 & 130.186 \\
\hline Alpha & $1 / \mathrm{h}$ & 0.188 & 8.701 & 0.148 & 14.864 \\
\hline Alpha $t^{1 / 2}$ & $\mathrm{~h}$ & 3.681 & 8.817 & 4.695 & 14.924 \\
\hline AUC & $\mathrm{h} \mathrm{ug} / \mathrm{ml}$ & 21.915 & 36.333 & 18.102 & 12.778 \\
\hline $\mathrm{B}$ & $\mathrm{ug} / \mathrm{ml}$ & 0.018 & 55.676 & 0.099 & 126.681 \\
\hline Beta & $1 / \mathrm{h}$ & 0.002 & 36.677 & 0.036 & 227.671 \\
\hline Beta $t^{1 / 2}$ & $\mathrm{~h}$ & 341.702 & 21.675 & 11.289 & 105.570 \\
\hline CMAX & $\mathrm{ug} / \mathrm{ml}$ & 0.934 & 20.799 & 1.013 & 23.908 \\
\hline K01 & $1 / \mathrm{h}$ & 0.217 & 10.821 & 0.198 & 31.149 \\
\hline K01 t1/2 & $\mathrm{h}$ & 3.189 & 10.882 & 3.501 & 31.256 \\
\hline TMAX & $\mathrm{h}$ & 9.243 & 14.389 & 8.175 & 16.586 \\
\hline Penetration & $\%$ & 160.588 & 20.644 & 94.388 & 26.063 \\
\hline
\end{tabular}

Table 2. Pharmacokinetic parameters for danofloxacin in interstitial fluid (ISF) dosed at $6 \mathrm{mg} / \mathrm{kg}$ under the skin every $48 \mathrm{~h}$ for two doses and $8 \mathrm{mg} / \mathrm{kg}$ under the skin once. $\mathrm{A}, \mathrm{B}$, the intercept for the initial and terminal portions of the curve, respectively. Alpha $(\alpha)$ and beta $(\beta)$ are the rate constants for the initial and terminal portions of the curves, with their respective half-lives $\left(\mathrm{t}^{1 / 2}\right)$. K01 is the absorption rate and corresponding halflife $\left(t^{1 / 2}\right)$. $C_{M A X}$ maximum drug concentration, $T_{M A X}$ time to maximum drug concentration.

\section{Danofloxacin in Cattle Two Dose, $6 \mathrm{mg} / \mathrm{kg}$}

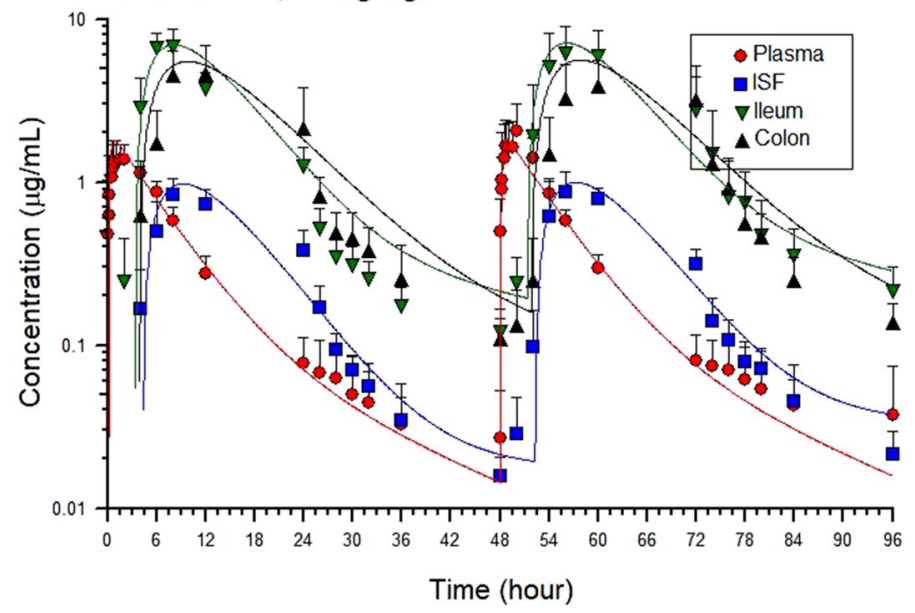

Figure 1. Total concentration of danofloxacin in plasma, interstitial fluid (ISF), ileum and colon ultrafiltrate dosed at $6 \mathrm{mg} / \mathrm{kg}$, once every $48 \mathrm{~h}$. Each point represents the mean and the error bars represent the standard deviation. The circle indicates plasma concentrations, the square indicates ISF concentrations, the upside down triangle indicates ileum ultrafiltrate concentrations and the right side up triangle indicates colon ultrafiltrate concentrations. The data is presented on a semi-logarithmic axis. The solid lines represent the predicted concentration based on the model fit. The actual values are the solid points.

For Enterococcus spp., the MIC median spiked for each dosing group after $96 \mathrm{~h}$. Although the medians per group were different, they remained above the zero time point for the rest of the study. Individual predetermined Wilcoxon-ranked sum tests were conducted. There was a significant difference between MIC values for E. coli at time point 0 compared to Day $6(144 \mathrm{~h}$ ) for the low dose group (Wilcoxon-ranked sum test, $\mathrm{p}=0.0005)$ and at time point 0 compared to Day $4(96 \mathrm{~h})$ for the high dose group (Wilcoxon-ranked sum test, $\mathrm{p}=0.006$ ). In addition, at Day $4(96 \mathrm{~h})$, there was a significant difference in MIC values for $E$. coli between the dosing groups (Wilcoxon-ranked sum test, $\mathrm{p}=3.4 \mathrm{e} 6)$ and at Day $6(144 \mathrm{~h}$, Wilcoxon-ranked sum test, $\mathrm{p}=0.00025)$. The MIC values were significantly higher in the low dose group when compared at Day 4 and Day 6. For Enterococcus, the only significant difference in MIC values was noted when comparing time point 0 to Day 6 for the low dose group $(\mathrm{p}=0.006)$.

To better visualize the changes in MIC values per dosing group for both E. coli and Enterococcus spp., heat maps were constructed. The heat maps demonstrate the number of bacterial isolates that had a value of the 


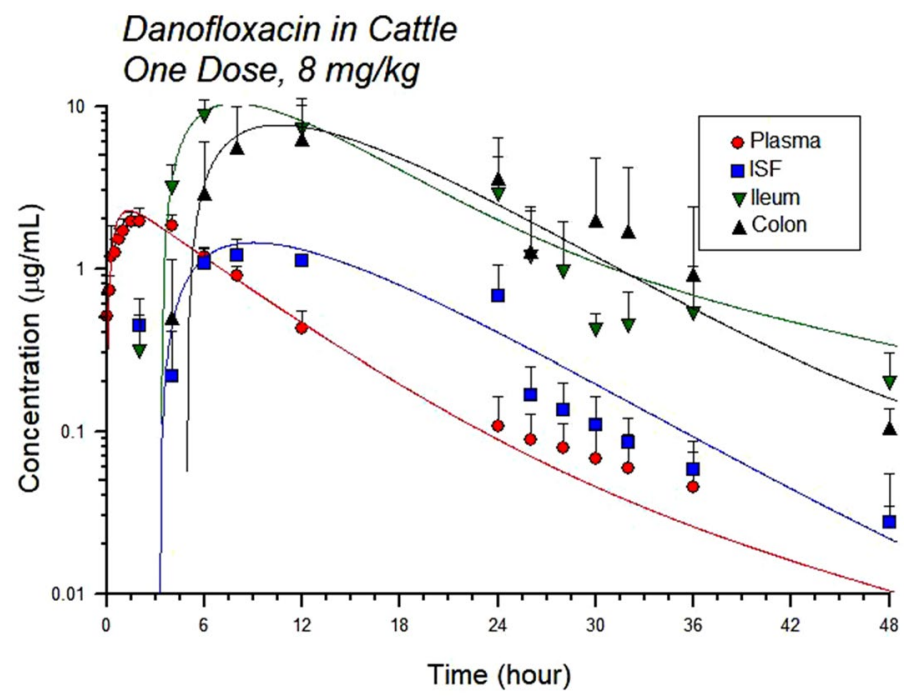

Figure 2. Total concentration of danofloxacin in plasma, interstitial fluid (ISF), ileum and colon ultrafiltrate dosed at $8 \mathrm{mg} / \mathrm{kg}$ once. Each point represents the mean and the error bars represent the standard deviation. The circle indicates plasma concentrations, the square indicates ISF concentrations, the upside down triangle indicates ileum ultrafiltrate concentrations and the right side up triangle indicates colon ultrafiltrate concentrations. The data is presented on a semi-logarithmic axis. The solid lines represent the predicted concentration based on the model fit. The actual values are the solid points.

\begin{tabular}{|c|c|c|c|c|c|}
\hline \multirow[b]{2}{*}{ Parameter } & \multirow[b]{2}{*}{ Units } & \multicolumn{2}{|l|}{$6 \mathrm{mg} / \mathrm{kg}$} & \multicolumn{2}{|l|}{$8 \mathrm{mg} / \mathrm{kg}$} \\
\hline & & Geometric mean & Geometric CV \% & Geometric mean & Geometric CV \% \\
\hline $\mathrm{A}$ & $\mathrm{ug} / \mathrm{ml}$ & 308.750 & 6.384 & 67.993 & 54.832 \\
\hline Alpha & $1 / \mathrm{h}$ & 0.207 & 12.018 & 0.199 & 12.708 \\
\hline Alpha $t^{1 / 2}$ & $\mathrm{~h}$ & 3.347 & 12.098 & 3.481 & 12.660 \\
\hline AUC & $\mathrm{h} \mathrm{ug} / \mathrm{ml}$ & 104.030 & 21.868 & 137.140 & 41.004 \\
\hline $\mathrm{B}$ & $\mathrm{ug} / \mathrm{ml}$ & 0.425 & 76.988 & 0.889 & 326.893 \\
\hline Beta & $1 / \mathrm{h}$ & 0.020 & 46.706 & 0.038 & 77.956 \\
\hline Beta $t^{1 / 2}$ & $\mathrm{~h}$ & 34.820 & 46.666 & 18.395 & 77.212 \\
\hline CMAX & $\mathrm{ug} / \mathrm{ml}$ & 6.889 & 13.081 & 9.083 & 23.704 \\
\hline K01 & $1 / \mathrm{h}$ & 0.220 & 11.733 & 0.274 & 13.407 \\
\hline K01 t $t^{1 / 2}$ & $\mathrm{~h}$ & 3.156 & 11.809 & 2.528 & 13.474 \\
\hline TMAX & $\mathrm{h}$ & 8.123 & 14.836 & 7.683 & 4.113 \\
\hline Penetration & $\%$ & 762.313 & 14.829 & 715.072 & 30.575 \\
\hline
\end{tabular}

Table 3. Pharmacokinetic parameters for danofloxacin in ileum ultrafiltrate dosed at $6 \mathrm{mg} / \mathrm{kg}$ under the skin every $48 \mathrm{~h}$ for two doses and $8 \mathrm{mg} / \mathrm{kg}$ under the skin once. A, B, the intercept for the initial and terminal portions of the curve, respectively. Alpha $(\alpha)$ and beta $(\beta)$ are the rate constants for the initial and terminal portions of the curves, with their respective half-lives $\left(t^{1 / 2}\right)$. K01 is the absorption rate and corresponding halflife $\left(\mathrm{t}^{1 / 2}\right) . C_{M A X}$ maximum drug concentration, $T_{M A X}$ time to maximum drug concentration.

designated MIC. These can be seen in Figs. 4 and 5. When looking at E. coli, in the high dose group (Fig. 4B), there are an increased number of isolates with MIC values ranging from 16 to $64 \mu \mathrm{g} / \mathrm{ml}$ over the $12 \mathrm{~h}$ to $72 \mathrm{~h}$ period. For the low dose group (Fig. 4A), there both an increase in variability of the MIC values and increased MIC values, ranging from 16 to $128 \mu \mathrm{g} / \mathrm{ml}$ over a longer period of time, $12 \mathrm{~h}$ to $144 \mathrm{~h}$ when compared to the high dose group. For Enterococcus, the low (Fig. 5A) and high dose (Fig. 5B) groups appear to look very similar. There is much more variation in the bacterial isolates's MIC values compared to E. coli isolates. The variation appears to last the entire study period.

Individual Enterococcus species were evaluated individually (Fig. 6). Multiple Enterococcus species can be seen throughout the study period, with Enterococcus hirae and Enterococcus faecium appearing most frequently. Enterococcus hirae, the most commonly isolated Enterococcus species isolated from bovine feces can be seen in Fig. 7. Increased range of MIC values is evident in both dosing groups. 


\begin{tabular}{|c|c|c|c|c|c|}
\hline \multirow[b]{2}{*}{ Parameter } & \multirow[b]{2}{*}{ Units } & \multicolumn{2}{|l|}{$6 \mathrm{mg} / \mathrm{kg}$} & \multicolumn{2}{|l|}{$8 \mathrm{mg} / \mathrm{kg}$} \\
\hline & & Geometric mean & Geometric CV \% & Geometric mean & Geometric CV \% \\
\hline $\mathrm{A}$ & $\mathrm{ug} / \mathrm{ml}$ & 331.907 & 9.860 & 40.642 & 486.117 \\
\hline Alpha & $1 / \mathrm{h}$ & 0.168 & 10.235 & 0.155 & 22.222 \\
\hline Alpha $t^{1 / 2}$ & $\mathrm{~h}$ & 4.115 & 10.262 & 4.457 & 22.125 \\
\hline AUC & $\mathrm{h} \mathrm{ug} / \mathrm{ml}$ & 84.318 & 45.630 & 106.836 & 179.445 \\
\hline $\mathrm{B}$ & $\mathrm{ug} / \mathrm{ml}$ & 0.343 & 140.751 & 0.164 & 84.429 \\
\hline Beta & $1 / \mathrm{h}$ & 0.030 & 45.670 & 0.016 & 109.624 \\
\hline Beta $t^{1 / 2}$ & $\mathrm{~h}$ & 23.318 & 46.105 & 42.468 & 106.580 \\
\hline $\mathrm{C}_{\operatorname{MAX}}$ & $\mathrm{ug} / \mathrm{ml}$ & 4.851 & 49.544 & 4.564 & 182.458 \\
\hline K01 & $1 / \mathrm{h}$ & 0.176 & 11.203 & 0.197 & 25.205 \\
\hline K01 t t⿳亠丷厂巾 & $\mathrm{h}$ & 3.947 & 11.135 & 4.438 & 87.278 \\
\hline $\mathrm{T}_{\text {MAX }}$ & $\mathrm{h}$ & 9.800 & 6.770 & 12.902 & 51.385 \\
\hline Penetration & $\%$ & 596.575 & 59.041 & 579.725 & 220.847 \\
\hline
\end{tabular}

Table 4. Pharmacokinetic parameters for danofloxacin in spiral colon ultrafiltrate dosed at $6 \mathrm{mg} / \mathrm{kg}$ under the skin every $48 \mathrm{~h}$ for two doses and $8 \mathrm{mg} / \mathrm{kg}$ under the skin once. $\mathrm{A}, \mathrm{B}$, the intercept for the initial and terminal portions of the curve, respectively. Alpha $(\alpha)$ and beta $(\beta)$ are the rate constants for the initial and terminal portions of the curves, with their respective half-lives $\left(\mathrm{t}^{1 / 2}\right)$. K01 is the absorption rate and corresponding halflife $(\mathrm{t} 1 / 2) . C_{M A X}$ maximum drug concentration, $T_{M A X}$ time to maximum drug concentration.

A
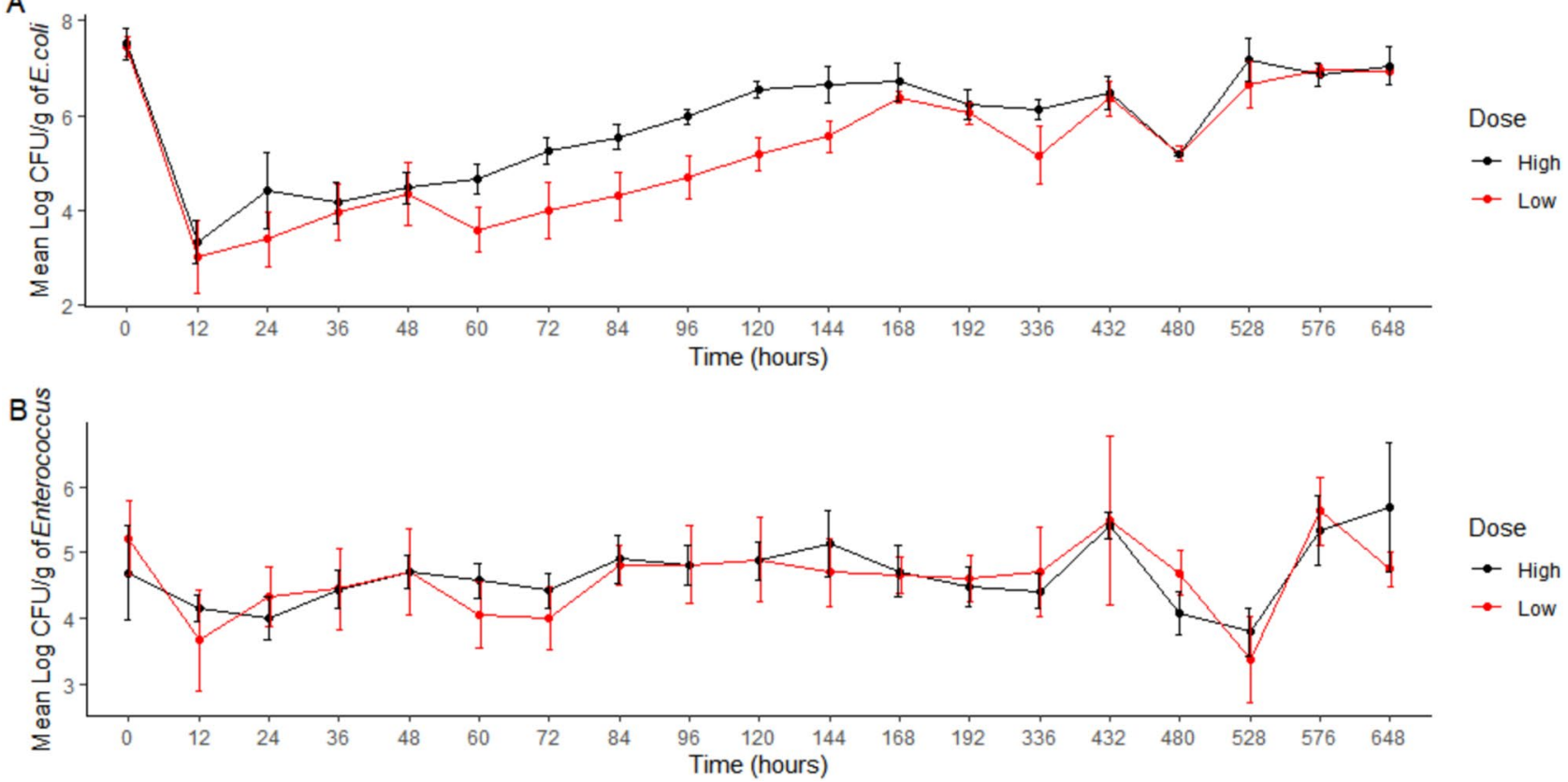

Figure 3. Mean Log CFU/g of E. coli and Enterococcus per dosing group over time with standard error. (A) Shows the Mean log CFU/g of $E$. coli while (B) shows the mean log CFU/g of Enterococcus. The black line is the high dose group and the red line is the low dose group. Individual t-tests with a Bonferonni correction $(\mathrm{p}<0.0125)$ were performed for overall $\log \mathrm{CFU} / \mathrm{g}$ at predetermined time points. The only significant difference seen for E. coli was comparing Day 0 to Day 6 for the low dose group only $(\mathrm{p}=0.0006)$. There was no significant differences noted for Enterococcus.

Alterations in the fecal microbiota. There appears to be a reduction in diversity based on Shannon Index after administration of danofloxacin, regardless of the dosing group (Fig. 8). However, it appears to rebound at the conclusion of the trial and is more similar to time point 0 , before danofloxacin administration. When assessing beta diversity, the samples had similar compositions (Fig. 8).

Euryarchaeota appears to be decreasing over time in both dosing groups, with no evident rebound (Fig. 9). This is due to a consistent decrease in Methanobacteriaceae across all animals (Supplementary Fig. S1). After $48 \mathrm{~h}$, regardless of the dose, there was a decrease in Methanobacteriaceae. This was sustained through the trial, with a slight increase in abundance at 7 days. 
A

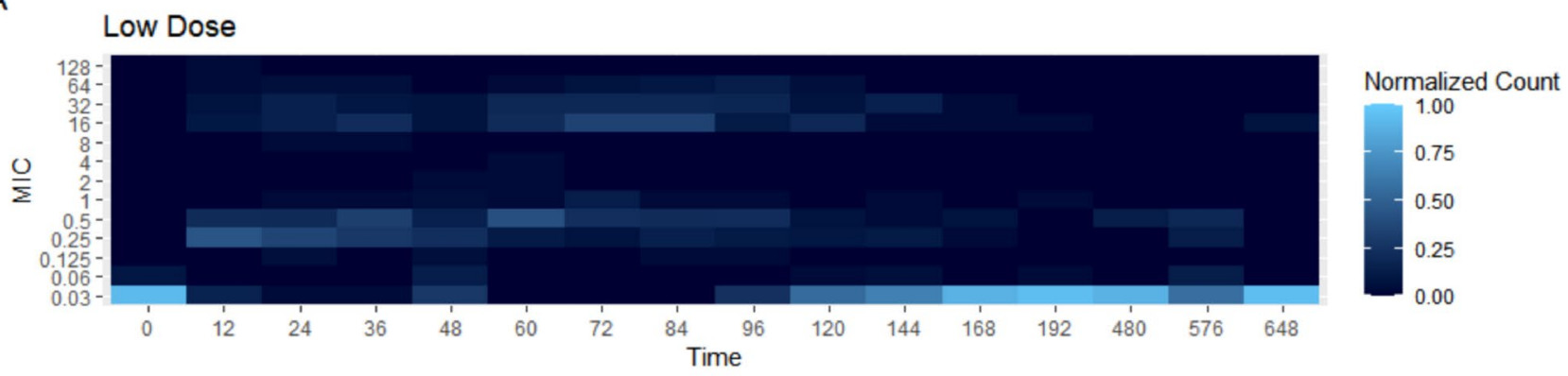

B

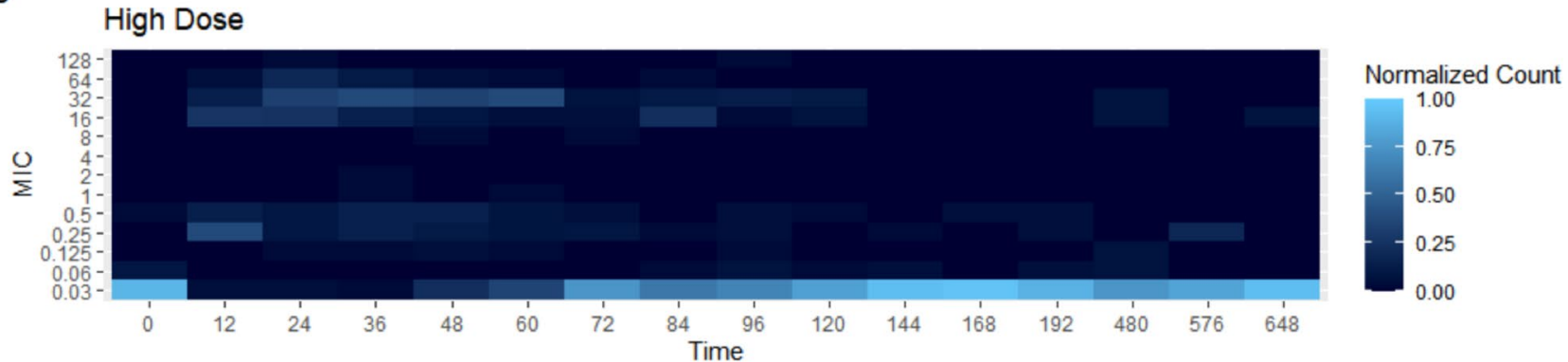

Figure 4. Heat Map demonstrating the number of $E$. coli isolates per each MIC value over time for both the low dose (A) and high dose group (B).

A

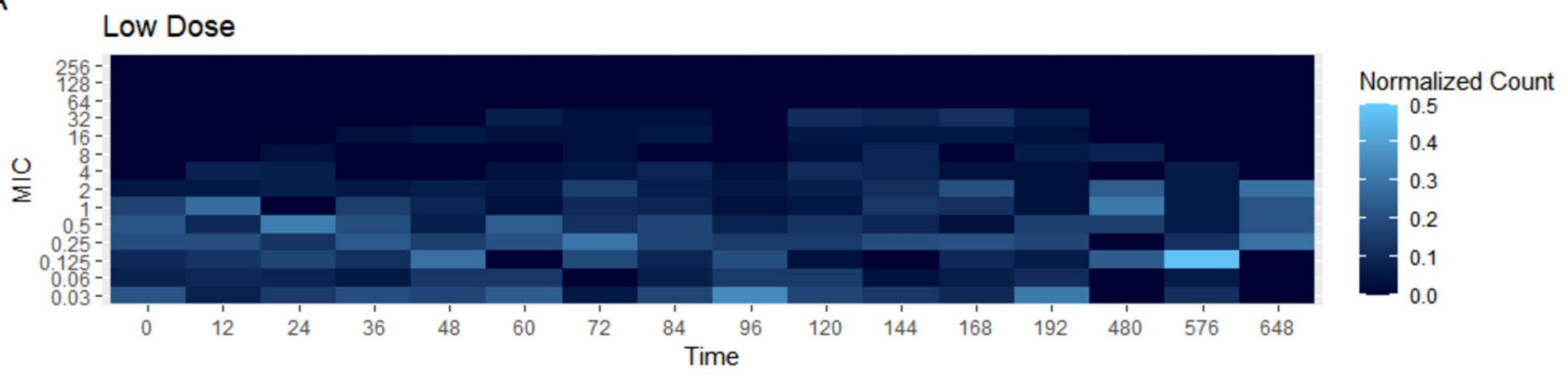

B

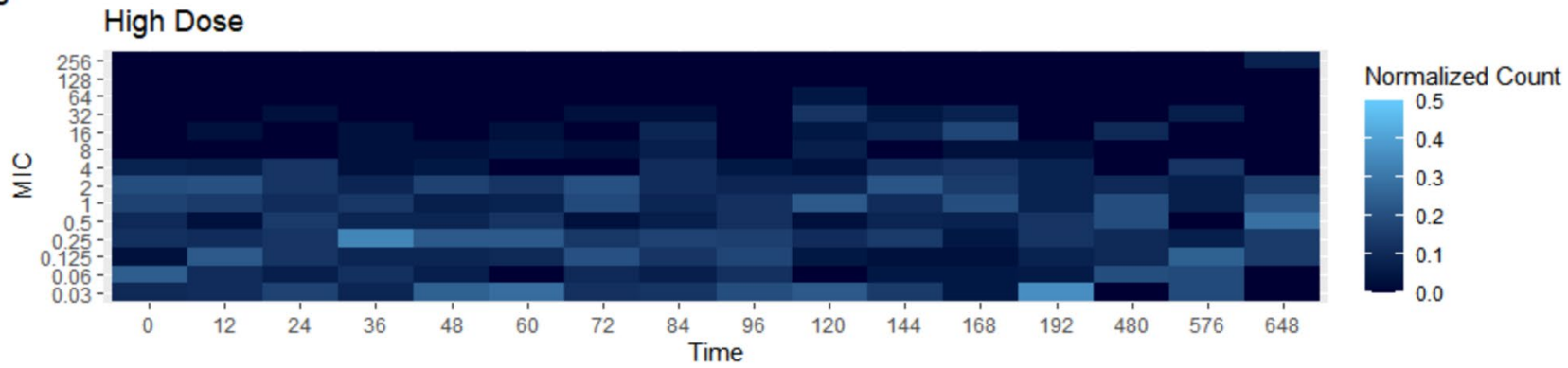

Figure 5. Heat Map demonstrating the number of Enterococcus isolates per each MIC value over time for both the low dose (A) and high dose group (B).

\section{Discussion}

Danofloxacin is a synthetic fluoroquinolone that is commonly used in veterinary medicine as treatment for bovine respiratory disease. The two different FDA-approved dosing regimens with a short meat withdrawal interval allow for it to be an attractive treatment option. For the single and multi-dose therapy, the meat withdrawal label is 4 days from the last dose. However, due to the growing threat of antimicrobial resistance and the critical designation of fluoroquinolones by the World Health Organization, understanding the relationship between gastrointestinal pharmacokinetics, changes in the gastrointestinal microbiome and phenotypic resistance are potentially useful to mitigate the public health threat of using danofloxacin in cattle.

In summary, the intestinal permeability was high for both dosing groups, and higher than what we observed for the intestinal pharmacokinetics of enrofloxacin ${ }^{14}$. The explanation for greater disposition of danofloxacin into intestinal fluids compared to enrofloxacin is undetermined. Fluoroquinolones are secreted into the intestine in 


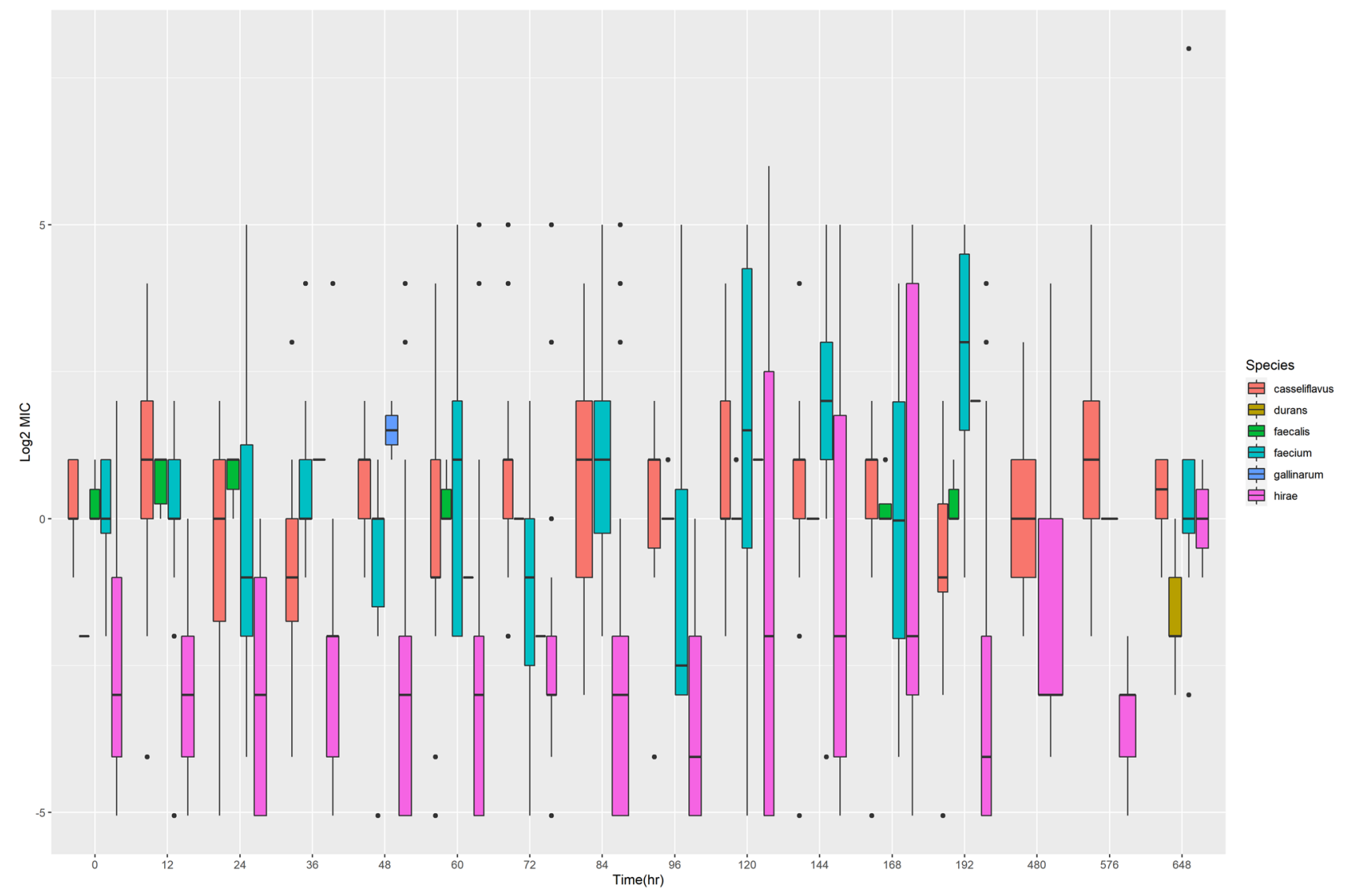

Figure 6. The Log 2 MIC value for the identified Enterococcus species over time. The Enterococcus species were determined via MALDI-TOF. The data is presented as a boxplots with the upper and low quartiles present. Outliers are shown as individual black circles. Present species include E. casseliflavus, E. durans, E. faecalis, E. faecium, E. gallinarum, E. hirae.

higher concentrations than plasma and interstitial fluid because of either active transport, or secretion in the bile, or both. The concentrations in the intestinal fluids were collected with an ultrafiltration device that collects only unbound drug. Therefore, the concentrations reported for intestinal fluids represents unbound, microbiologically active drug concentrations. These high concentrations have profound effects on the population of bacteria in the intestine. We also observed high interstitial fluid (ISF) concentrations from both the high and low dose. This may reflect a persistence in tissues for longer than anticipated, and longer than predicted from the unbound drug concentration in plasma. The protein binding reported for two concentrations produces an unbound fraction $(f u)$ of approximately 0.6 . Ordinarily the unbound concentration in plasma is expected to equilibrate with the unbound concentration in tissue fluids; however, the concentration in ISF far exceeded this fraction.

The concentration of $E$. coli, as determined by calculating the $\log _{10} \mathrm{CFU} / \mathrm{g}$ of feces appears to decrease dramatically after antibiotic administration, which is again similar to enrofloxacin ${ }^{14}$. Over time, the CFU/g reached a similar starting point to baseline $(0 \mathrm{~h})$. This rebound concentration of $E$. coli was delayed in these steers treated with danofloxacin when compared to those treated with enrofloxacin ${ }^{14}$. The median MIC was the same at each time point for E. coli, regardless of the dosing group. However, when looking at the individual values, there was a significant difference in MIC value between dosing groups at Day 4 and Day 6 for E. coli, with the low dose group being significantly higher at both time points. Further, a notable increase in the MIC of some isolates was seen as early as $12 \mathrm{~h}$ in both groups with isolates with an MIC of $32 \mathrm{ug} / \mathrm{ml}$ being found out to $144 \mathrm{~h}$ after initial treatment in the low dose group but only until $96 \mathrm{~h}$ in the high dose group.

Enterococcus growth is more stable over time as it does not appear to be influenced by administration of danofloxacin. When the MIC of all Enterococcus isolates were analyzed together, there were no significant differences between treatment groups, but significant differences were seen based on the speciation of Enterococcus. Enterococcus hirae is the most common Enterococcus species found in cattle ${ }^{15}$. Although it is not a significant pathogen in humans, its increased presence could potentially allow for sharing of AMR genes with other species that are more significant human disease, including Enterococcus faecalis and Enterococcus faecium, which are frequently implicated in nosocomial human infections. We were able to see wide ranges in MIC values for all these Enterococcus spp., which persisted beyond the labeled withdrawal time for danofloxacin. Enterococcus faecium appeared to have a wider MIC range in cattle dosed with the lower, multi-dose therapy. This was in contrast to Enterococcus hirae, which was found to have a wider MIC range in the higher single dose therapy. Interestingly, Enterococcus faecalis was only found in the high dosed group. The reason for this was not apparent. 


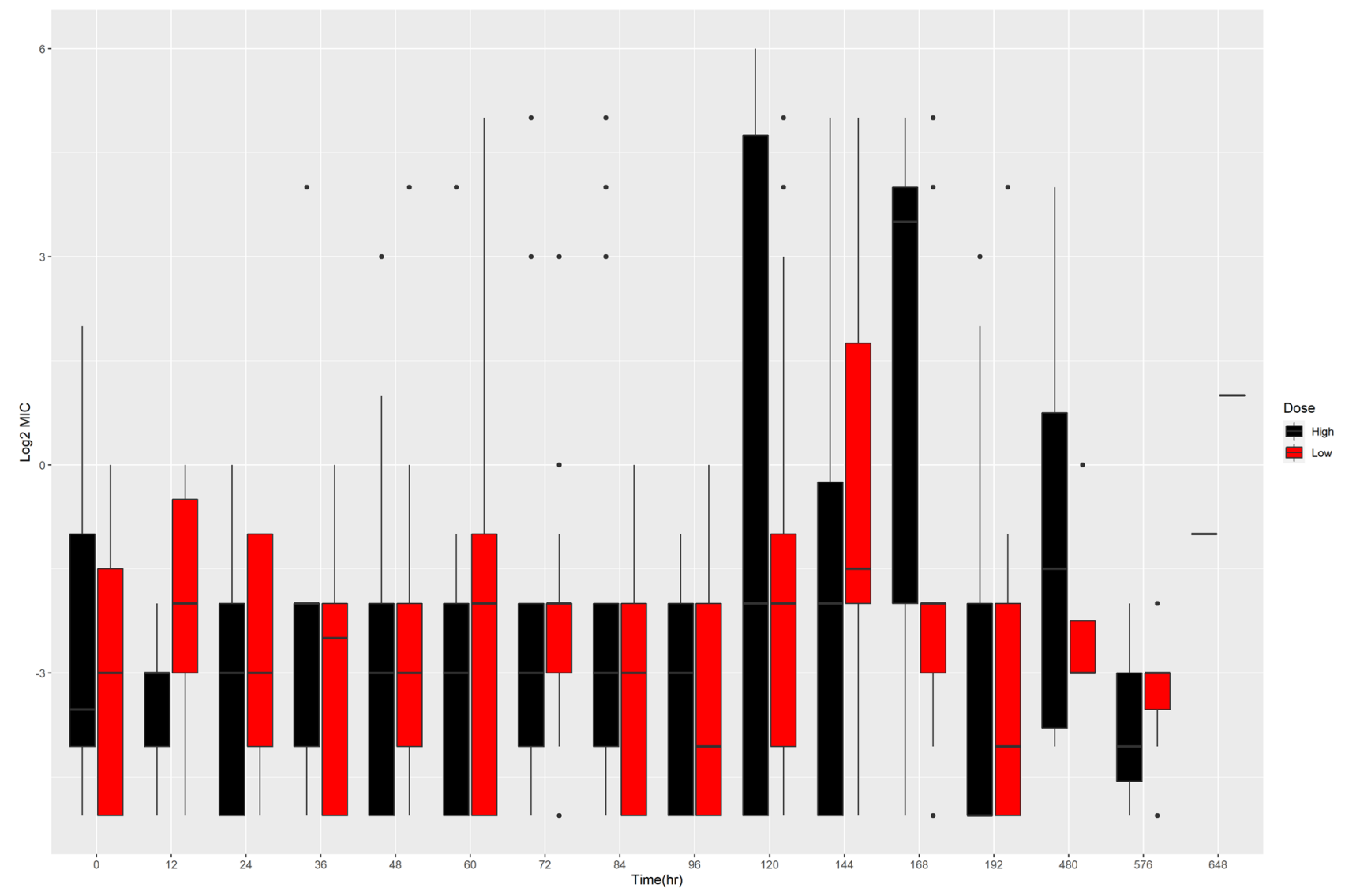

Figure 7. Log2 MIC over time of Enterococcus hirae per dosing group. The high dose group is shown in black and the low dose group is shown in red. The data is presented as boxplots with the upper and low quartiles present. Outliers are shown as individual black circles.

As danofloxacin targets bovine respiratory pathogens, break points have been established only for bacteria associated with bovine respiratory disease, Mannheimia haemolytic and Pasteurella multocida ${ }^{16}$. In contrast, break points for E. coli and Enterococcus for danofloxacin in the gastrointestinal tract have not been established, making it impossible to classify these organisms as resistant or susceptible in our study. Nonetheless, there are many isolates found soon after treatment with MIC values well beyond the typical goal of an AUC/MIC $>100$ based on our PK data ${ }^{17}$. Analyzing the aggregate MIC data is quite difficult since it is not normally distributed and quite variable. Because of these challenges, we felt that analyzing the median MIC values was the most appropriate. For this data, the lower dose group has significantly higher MIC values compared to the high dose group for E. coli at Day 4 and Day 6, the meat withdrawal times for each dosing group. The increased MIC value suggests that the E. coli in the low dose group have an increased tolerance to danofloxacin compared to the high dose group $E$. coli. This would concur with the inverted $U$ paradigm of building increased tolerance, or resistance, to bacteria that are exposed to sub-therapeutic levels of antibiotic early in the course of therapy ${ }^{18}$. In terms of reducing antibiotic resistance, an increase in the meat withdrawal interval may be warranted allow for a decrease in the tolerance of $E$. coli to danofloxacin prior to an animal entering the food chain in order to limit the possible transmission of resistance.

Although no differences were seen for Enterococcus MIC when all species were analyzed together, the MIC per species was different depending upon the dosing group. As stated previously, Enterococcus faecium was shown to have a wider MIC range in the lower dosed group that persisted for a longer time period. This too concurs with the inverted U paradigm. However, the distribution of MIC of Enterococcus hirae is in contrast to the inverted $\mathrm{U}$ paradigm and our hypothesis, although there is a spike in a wide distribution of MIC values for the low dose group later in the time course, and both groups return to relatively low MIC values by the end of the study.

Aside from the decrease in Methanobacteriaceae, the microbial population remains rather constant throughout the study period, despite danofloxacin's high intestinal penetration. The genus Methanobrevibacter is one of the dominant methanogens present in ruminants, comprising between 0.5 and $3 \%$ of the total bacterial population in ruminants ${ }^{19,20}$. Methanogens are responsible for the production of methane after fermentation occurs. After danofloxacin administration, here, we see this phylum decreases and does not rebound. The composition of methanogens present in the rumen will effect cattle feed efficiency. In this study, we were unable to determine the species level to see which methanogens were no longer present and how they would contribute to feed efficiency. Further, our data is based on fecal composition, and it is unclear if these changes are reflected in the rumen, the primary site of methane production. 


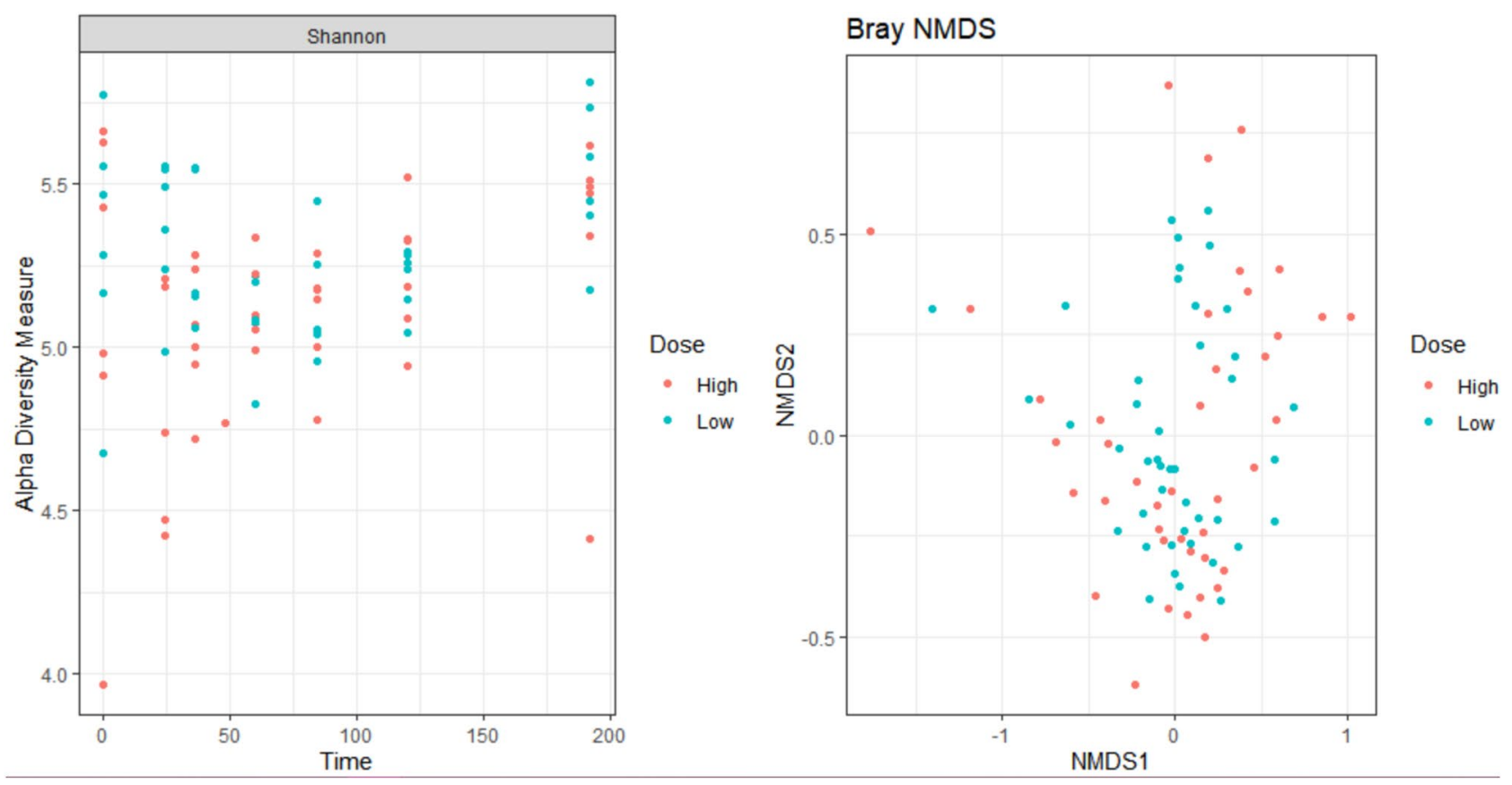

Figure 8. Shannon Diversity Index and Bray-Curtis plot assessing beta diversity. This is a Shannon Index diversity plot comparing the diversity of the samples between the high (orange) and low dose (blue) group. The higher the value on the $y$ axis indicates there is more diversity in the microbial community. This is a Bray-Curtis plot to assess the beta diversity, or look at the variance across all the samples. The high dose group samples are shown in orange and the low dose group samples are shown in blue. The Bray-Curtis plot measures how dissimilar the samples are.

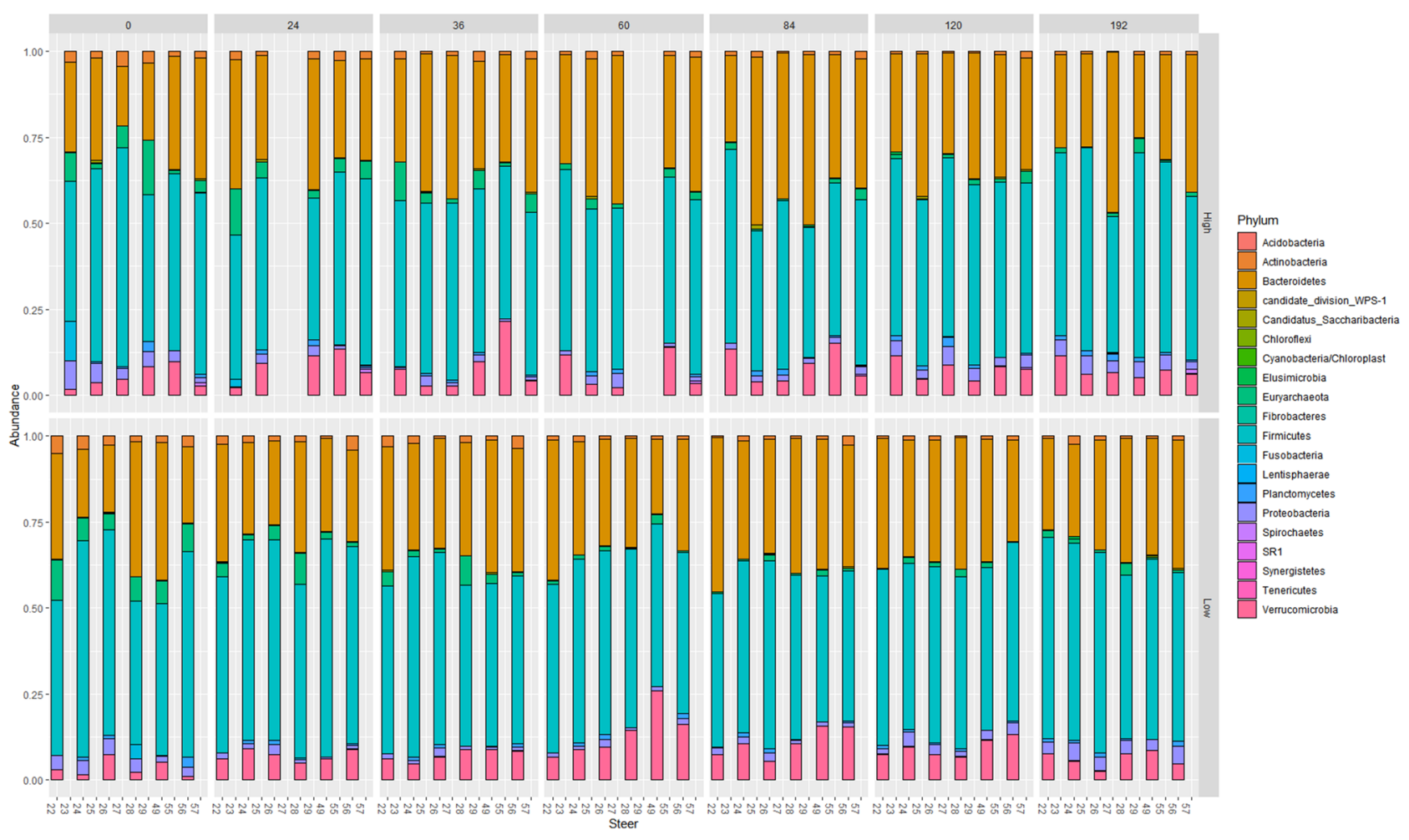

Figure 9. Relative abundance plotting of Phylum over time per dosing group. A relative abundance plot demonstrating the change in microbial composition (at the Phylum level) over time for each individual steer per high and low dose group. 
A major limitation in interpreting the public health importance of this study is the inability to classify recovered bacteria as susceptible, intermediate or resistant isolates for both E. coli and Enterococcus towards danofloxacin. A long term goal is to develop a microbial withdrawal interval after administration of veterinary therapeutic drugs. A microbial withdrawal interval would allow for a duration of time to pass after administration of the therapeutic to minimize the likelihood of enteric bacteria resistant to drugs of human consequence to spread through the food chain as direct pathogens or reservoirs of resistance. Although there are still many unknown components and more questions to the development of a microbial withdrawal interval, demonstrating the impact of dosing regimens for danofloxacin on MIC values of E. coli and Enterococcus populations over time demonstrate when and if the population will return to a wildtype population in the absence of antibiotic pressure. Finally, the sequencing of 16s RNA is only used to identify different taxa of bacteria present within the same, usually to the genus level, we were not able to remark on any specific AMR genes that may have been shared with the different bacterial organisms. This may be an important area to investigate in future studies.

In conclusion, both dosing regimens have high intestinal penetration, yet the changes to the fecal microbiome are minor and transient. E. coli concentration decreases after administration of danofloxacin, but it returns to baseline at the end of the study period. Regardless of the dosing group, Enterococcus spp. appear to have a wide variation in MIC that persists well beyond the labeled withdrawal interval for danofloxacin. Though there are some expected Enterococcus species differences, in general the lower dose regimen leads to prolonged increases in MIC of both E. coli and Enterococcus spp. when compared to the single, high-dose regimen. This will need to be taken into consideration for the development of a microbial withdrawal interval if this approach is to be successful in mitigating resistance associated with use of danofloxacin in cattle.

\section{Materials and methods}

Animals, surgical procedure and treatment. This study was approved by North Carolina State University's Intuitional Animal Care and Use Committee and the care of the steers was in agreement with their policies, as well as in accordance with the guidelines and regulations from this journal (and ARRIVE guidelines). Twelve healthy 6-7 month old steers $(219-310 \mathrm{~kg})$ were enrolled in the study. The study size was based on previous gastrointestinal pharmacokinetic studies in order to demonstrate differences between the two dosing regimens ${ }^{12,21,22}$. They were judged healthy by a physical exam on presentation, with no previous documentation of any antimicrobial administration. After a 3 day period of acclimation, the steers underwent gastrointestinal surgery to facilitate placement of ultrafiltration probes, as previously described ${ }^{12,21,22}$. The steers were clipped and sterilely prepped on their right flank. A distal paravertebral block with lidocaine was used to provide anesthesia to the right paralumbar fossa. A linear vertical incision was made. Upon entering the abdomen, the cecum was found. Just orad to the cecum, a segment of ileum was exteriorized through the abdominal incision. A small incision was made in the ileum and the collecting loops of the ultrafiltration probe (UF-3-12, BAS; Bioanalytical Systems, West Lafayette, IN, USA) were introduced into the lumen via an introducer needle. A purse-string suture pattern was applied to secure the ultrafiltration probe. The same procedure was performed to place an ultrafiltration probe into the lumen of the spiral colon. The free ends of the ultrafiltration probes were brought out of the abdomen near the abdominal incision. The flank incision was closed in a routine manner. At the time of surgery, steers received intravenous flunixin meglumine ( $2 \mathrm{mg} / \mathrm{kg}$, Banamine, Merck Animal Health, Madison, NJ, USA).

Twenty-four to $48 \mathrm{~h}$ after surgery, the steers were dosed with either $6 \mathrm{mg} / \mathrm{kg}$ danofloxacin (Advocin; Zoetis, Kalamazoo, MI, USA) subcutaneously every $48 \mathrm{~h}(\mathrm{n}=6$, for a total of two doses) or a single $8 \mathrm{mg} / \mathrm{kg}$ subcutaneous dose ( $n=6$, a single dose). The steers were housed in pairs (one from each treatment group) and fed grass hay with supplemental grain and free access to water for the duration of the study.

Collection of plasma. To facilitate blood collection, prior to surgery, an intravenous jugular catheter (Angiocath, Becton Dickinson Infusion Therapy Systems Inc. Sandy, UT, USA) was placed. Blood was obtained at $0,15,30,45,60$ and $90 \mathrm{~min}$, and 2, 4, 8, 12, 24, 36, $48 \mathrm{~h}, 48 \mathrm{~h} 15 \mathrm{~min}, 48 \mathrm{~h} 30 \mathrm{~min}, 49,50,52,56,60,72,84,96$, 120,144 and $168 \mathrm{~h}$. The blood was centrifuged within an hour after collection at $1000 \times g$ for $10 \mathrm{~min}$. The plasma was transferred to cyrovials and stored at $-80{ }^{\circ} \mathrm{C}$ until analysis.

Collection of interstitial fluid and intestinal ultrafiltrate. After the completion of surgery with properly placed ultrafiltration probes, the free ends of the ultrafiltration probes from the ileum and spiral colon were connected to a $3 \mathrm{ml}$ evacuated tube with no additive (Vacutainer R, Becton-Dickinson, Franklin Lakes, NJ, USA). This was done by connecting the probe onto a needle of the vacuum vial needle holder at the end of the tubing. The external tubing was sutured in place along the flank. Intestinal ultrafiltrate was collected by changing the tubes at the following time points: $0,2,4,6,8,12,24,26,28,30,32,36,48,72$ and 96 h post high-dose drug administration, and additionally $50,52,54,56,60,74,76,78,80$, and 84 h post low-dose drug administration The fluid was transferred into cyrovials and stored at $-80{ }^{\circ} \mathrm{C}$.

An ultrafiltration probe was also used to collect interstitial fluid (ISF); this probe was placed in the subcutaneous space at the withers. The free end of the probe was connected to an evacuated tube in the same fashion and suture along the back. The evacuated tube was changed at $0,2,4,8,12,24,36,48,50,52,56,60,72,84,96,120$, 144 and $168 \mathrm{~h}$. The fluid was transferred into cyrovials and stored at $-80{ }^{\circ} \mathrm{C}$.

Collection of feces. Feces was collected manually from the rectum. Time points for feces collection were 0 , $12,24,36,48,60,72,84,96,120,144,168,192,336,432,480,528,576$, and 648 h post first drug administration. The samples were placed into bags (Whirlpak, Nasco, Fort Atkinson, WI, USA) and stored on ice. Within an hour of collection, feces stored on ice was used for microbiological analysis. Additionally, 2 aliquots of feces were placed in cyrovials and stored at $-80{ }^{\circ} \mathrm{C}$ for future use. 
Drug concentration analysis. The samples were analyzed for danofloxacin using a high-pressure liquid chromatography (HPLC) with UV absorbance detection for plasma samples and fluorescence detection for tissue fluids with methods previously used for studies with enrofloxacin in calves ${ }^{12,21}$, but with modifications to the assay optimized for danofloxacin as described in another paper ${ }^{23}$. The plasma assay was performed using solid phase extraction, with $400 \mu \mathrm{l}$ of plasma added to the extraction cartridge as described previously ${ }^{12}$. The ISF, colon, and ileum fluid samples were analyzed directly (without extraction) because the fluid already represented a protein-free ultrafiltrate. A validation of the assay was performed by fortifying blank plasma, or other fluids (phosphate buffered saline, HyClone, VWR, Radnor, PA, USA) with a danofloxacin analytical reference standard (Vetranal, Sigma-Aldrich, St. Louis, MO, USA) to produce concentrations for a calibration curve and quality control (QC) samples. Blank (control) samples were analyzed to measure background noise and verify that there were no interfering peaks in the chromatograms for the retention time of interest. Accuracy of the method was approximately $100 \%$ for all the spiked samples (99-101\%) across the range of all concentrations. All of the spiked concentrations fell within our threshold cutoff of $15 \%$.

Pharmacokinetic analysis. The pharmacokinetic analysis is similar to those performed in previous studies $^{12,21,22}$. The drug concentrations were analyzed using compartmental pharmacokinetic methods to determine the drug disposition in each calf. A computer program (Phoenix WinNonlin, V. 8.0; Certara, St. Louis, MO, USA) was used to determine the values for pharmacokinetic parameters. Plasma, ISF, and intestinal drug concentrations were plotted on linear and semi-logarithmic graphs for analysis and for visual assessment of the best model for pharmacokinetic analysis. Specific models (e.g., one, two, etc. compartments) were determined for best fit based on visual analysis for goodness of fit and by visual inspection of residual plots. The best model fit was based on the equation described in the following formula:

$$
C=A^{-\alpha t}+B^{-\beta t}+C^{-K 01}
$$

where $\mathrm{C}$ is the plasma concentration, $\mathrm{t}$ is time, $\mathrm{K} 01$ is the non-IV absorption rate, assuming first-order absorption, $\alpha$ is the initial steep portion of the concentration curve, and $\beta$ is the slower terminal slope of the concentration curve. The analysis conducted is similar to previously described methods ${ }^{12,21,22}$. Secondary parameters calculated from the model included the peak concentration (CMAX), time to peak concentration (TMAX), area under the plasma-concentration vs. time profile (AUC), and the respective half-lives $\left(\mathrm{t}^{1 / 2}\right)$ from each of the rate constants. The relative drug transfer from the plasma compartment to the ISF and intestinal fluids was measured by calculation of a penetration factor. The penetration factor was determined by the ratio of AUC for the tissue fluid (ISF, ileum, or colon) to the AUC for plasma:

Penetration factor $=$ AUC tissue fluid or ISF/AUC plasma.

Individual student $t$ tests were used to determine significance between dosing groups for the following pharmacokinetic parameters for all fluid types (plasma, interstitial fluid and intestinal ultrafiltrate): AUC, half-life, $\mathrm{C}_{\mathrm{MAX}}, \mathrm{T}_{\mathrm{MAX}}$ and intestinal penetration.

Protein binding. Plasma protein binding was calculated as described in previous publications ${ }^{12,21}$.

Plasma protein binding was performed with a micropartition device (CentrifreeMicropartition system, Amicon Millipore, Billerica, MA, USA). Aliquots of pooled calf plasma collected prior to drug administration were spiked with danofloxacin at two concentrations $(0.5$ and $1.0 \mu \mathrm{g} / \mathrm{ml})$ to represent concentrations in the range of those measured during the study, in replicates of 3. A $1 \mathrm{ml}$ sample was added to the micropartition system to obtain a protein-free ultrafiltrate for HPLC analysis. A second set of three replicates of spiked plasma at the same concentrations were processed as described previously and analyzed by HPLC for comparison. Protein binding was determined by use of the following equation:

$$
\% \text { Protein binding }=\frac{[\text { Total concentration }]-[\text { Protein unbound concentration }]}{[\text { Total concentration }]} \text {. }
$$

Quantification of E. coli and Enterococcus from Feces. One gram of feces was weighed and placed into either $9 \mathrm{ml}$ of EC broth (EC broth, Oxoid Ltd., Basingstoke, Hampshire, England) for E. coli growth or $9 \mathrm{ml}$ of PBS for Enterococcus growth. The samples were vortexed and subsequently serially diluted tenfold into sterile phosphate buffer. The diluted samples were plated in triplicate (100 ul) on selective media; E. coli dilutions were plated onto HardyCHROM ECC (Hardy Diagnostics, Santa Maria, CA, USA) and Enterococcus dilutions onto Difco Enterococcus Agar (Becton, Dickinson and Company, Sparks, MD, USA). The HardyCHROM plates were incubated for $18-24 \mathrm{~h}$ at $37^{\circ} \mathrm{C}$, while the Difco plates were incubated for $48 \mathrm{~h}$ at $37^{\circ} \mathrm{C}$. Dilutions that yielded colony counts of 30-300 were used; the three replicates had colony counts performed and were averaged to determine the quantity of both E. coli and Enterococcus at each time point. From the three plates that were used to determine the quantity of E. coli and Enterococcus, 8 isolates in total were randomly selected and were streaked for isolation onto Columbia agar with $5 \%$ sheep blood (Remel, Lenexa, KS, USA) and incubated overnight at $37^{\circ} \mathrm{C}$. After incubation, each suspected $E$. coli isolate was indole tested (Indole Reagent Kovacs, Remel, Lenexa, KS, USA). Each isolate was then stored in a cryogenic vial containing LB Broth (Sigma-Aldrich, St. Louis, MO, USA) supplemented with 25\% glycerol (Fisher BioReagents, Fisher Scientific, Waltham, MA, USA). They were vortexed and frozen at $-80^{\circ} \mathrm{C}$ as a pure growth. Enterococcus isolates were speciated using MALDI-TOF mass spectrometry and then stored as described above. 
Determining the minimum inhibitory concentration. The minimum inhibitory concentration (MIC) of each E. coli and Enterococcus isolate was determined utilizing broth microdilution according to Clinical and Laboratory Standards Institute guidelines ${ }^{24}$. Briefly, each isolate was grown overnight on blood agar; the following day, a single isolate was collected with a sterile loop and suspended in Mueller Hinton broth (BBL Mueller-Hinton II Broth, cation adjusted, Becton, Dickinson, and Company, Sparks, MD, USA) to achieve 0.5 McFarland Standard. Fifty microliters of the bacterial suspension were added into $50 \mathrm{ul}$ of twofold dilutions of danofloxacin ranging from 0.03 to $64 \mu \mathrm{g} / \mathrm{ml}$. If there was growth at all concentrations, the isolate was similarly grown using concentrations that ranged from 64 to $256 \mathrm{ug} / \mathrm{ml}$ (Danofloxacin VETRANAL analytical standard, SIGMA-ALDRICH, Inc. St. Louis, MO, USA). The plates were incubated overnight at $37^{\circ} \mathrm{C}$. The first well with no visible growth was determined to be the MIC.

DNA extraction from feces. Fecal sample DNA was extracted using Qiagen MagAttract PowerMicrobiome kit DNA/RNA kit (Qiagen, catalog no. 27500-4-EP) at the University of Michigan Center for Microbial Systems. The DNA libraries were prepared for analysis as previously described by Seekatz et al. ${ }^{25}$.

16s rRNA sequencing and microbiome analysis. The V4 region of the 16s rRNA was amplified using barcoded dual index primers ${ }^{26}$. Polymerase chain reactions were conducted and normalized using SequalPrep Normalization Plate Kit (Thermo Fisher Scientific, catalog no. A105100). The normalized reactions were then pooled and quantified using Kapa Biosystems Library qPCR MasterMix Quantification kit (catalog no. KK4873). Samples were sequenced on the Illumina MiSeq platform using the 500 cycle MiSeq V2 Reagent Kit (catalog no. MS-102-2003).

The FASTQ sequences were analyzed using the DADA2 method ${ }^{27,28}$. Amplicon sequence variants (ASV) were compiled using the DADA2 tutorial (https://benjjneb.github.io/dada2/tutorial.html). Briefly, after assessing the quality of both the forward and reverse reads, the forward and reverse reads were filtered and trimmed. Error rates were determined, as well as the number of unique sequences per sample submission. The forward and reverse reads were then merged and chimeras removed. Taxonomy was assigned using the RDP training set.

Statistical analysis. Individual Wilcoxon ranked sum tests were used to determine significance between dosing groups for the following pharmacokinetic parameters for all fluid types (plasma, interstitial fluid and intestinal ultrafiltrate): AUC, half-life, $\mathrm{C}_{\mathrm{MAX}}$ and $\mathrm{T}_{\mathrm{MAX}}$.

Descriptive statistics of MIC values for both E. coli and Enterococcus were determined. Predetermined individual Wilcoxon-Ranked Sum tests were conducted to assess MIC values for each organism at high dose group day 4 to day 0 , low dose group day 6 to day 0, both groups compared at Day 6 and at Day 4 . To construct the heat maps, the isolates per time point per dosing group were normalized to prevent any spurious data. Statistical analysis was conducted utilizing R Software ${ }^{23}$.

Received: 11 September 2020; Accepted: 21 April 2021

Published online: 27 May 2021

\section{References}

1. Pfizer. Freedom of Information Summary Advocin 2011, NADA 141-207.

2. U.S. Department of Health and Human Services. Guidance for Industry: Evaluating the Safety of Antimicrobial New Animal Drugs with Regard to Their Microbiological Effects on Bacteria of Human Health Concerns (2003). https://www.fda.gov/regulatory-infor mation/search-fda-guidance-documents/cvm-gfi-152-evaluating-safety-antimicrobial-new-animal-drugs-regard-their-microbiolo gical-effects. Accessed (2019)

3. Price, L. B. et al. Elevated risk of carrying gentamicin-resistant Escherichia coli among U.S. poultry workers. Environ. Health Perspect. 115, 1738-1742 (2007).

4. Van den Bogaard, A. E. \& Stobberingh, E. E. Epidemiology of resistance to antibiotics. Links between animals and humans. Int. J. Antimicrob. Agents 14, 327-335 (2000).

5. Jacoby, G. A. Mechanism of resistance to quinolones. Clin. Infect. Dis. 4, S120-S126 (2005).

6. Hooper, D. C. \& Jacoby, G. A. Mechanisms of drug resistance: Quinolone resistance. Ann. N. Y. Acad. Sci. 1354(1), 12-31 (2015).

7. Durso, L. M. et al. Virulence-associated and antibiotic resistance genes of microbial populations in cattle feces analyzed using a metagenomics approach. J. Microbiol. Methods 84, 278-282 (2010).

8. Thurston-Enriquez, J. A., Gilley, J. E. \& Eghball, B. Microbial quality of runoff following land application of cattle manure and swine slurry. J. Water Health 3, 157-171 (2005).

9. Mootian, G., Wu, W. H. \& Matthews, K. R. Transfer of Escherichia coli O157:H7 from soil, water and manure contaminated with low numbers of the pathogen to lettuce plants. J. Food Prot. 72, 2308-2312 (2009).

10. Martinez, M. N. et al. Dosing regimen matters: The importance of early intervention and rapid attainment of the pharmacokinetic/ pharmacodynamics target. AAC 56(6), 2795-2805 (2012).

11. Ferran, A. A. et al. Pharmacokinetic/pharmacodynamic assessment of the effects of parenteral administration of a fluoroquinolone on the intestinal microbiota: Comparison of bactericidal activity at the gut versus the systemic level in a pig model. Int. J. Antimicrob. Agents 42, 429-435. https://doi.org/10.1016/j.ijantimicag.2013.07.008 (2013).

12. Foster, D. M., Jacob, M. E., Warren, C. D. \& Papich, M. G. Pharmacokinetics of enrofloxacin and ceftiofur in plasma, interstitial fluid, and gastrointestinal tract of calves after subcutaneous injection, and bactericidal impacts on representative enteric bacteria. J. Vet. Pharmacol. Ther. 39, 62-71. https://doi.org/10.1111/jvp.12236 (2016).

13. Lindecrona, R. H., Friis, C. \& Nielsen, J. P. Pharmacokinetics and penetration of danofloxacin into the gastrointestinal tract in healthy and in Salmonella typhimurium infected pigs. Res. Vet. Sci. 68, 211-216. https://doi.org/10.1053/rvsc.1999.0361 (2000).

14. Ferguson, K. M. et al. Dosing regimen of enrofloxacin impacts intestinal pharmacokinetics and the fecal microbiota in steers. Front. Microbiol. 9, 2190 (2018).

15. Beukers, et al. Comparative genomics of Enterococcus spp. isolated from bovine species. BMC Microbiol. 17, 52. https://doi.org/ 10.1186/s12866-017-0962-1 (2017) 
16. Sweeney, M. T. et al. New interpretive criteria for danofloxacin antibacterial susceptibility testing against Mannheimia haemolytica and Pasteurella multocida associated with bovine respiratory disease. J. Vet. Diagn. Investig. 29(2), 224-227 (2017).

17. Craig, W. A. Does the dose matter?. Clin. Infect. Dis. 33(Suppl 3), S233-S237 (2001).

18. Martinez, M. N., Papich, M. G. \& Drusano, G. L. Dosing regimen matters: The importance of early intervention and rapid attainment of the pharmacokinetic/pharmacodynamics target. Antimicrob. Agents Chemother. 56(6), 2795-2805 (2012).

19. Ufnar, J. A. et al. Methanobrevibacter ruminantium as an indicator of domesticated-ruminant fecal pollution in surface waters. Appl. Environ. Microbiol. 73(21), 7118-7121 (2017).

20. Lin, C. et al. Microbial community structure in gastrointestinal tracts of domesticated animals: Comparative analyses using rRNAtargeted oligonucleotide probes. FEMS Microbiol. Ecol. 22, 281-294 (1997).

21. Davis, J. L., Foster, D. M. \& Papich, M. G. Pharmacokinetics and tissue distribution of enrofloxacin and its active metabolite ciprofloxacin in calves. J. Vet. Pharmacol. Ther. 30, 564-571. https://doi.org/10.1111/j.1365-2885.2007.00914 (2007).

22. Foster, D. M. et al. Ceftiofur formulation differentially affects the intestinal drug concentration, resistance of fecal Escherichia coli and the microbiome of steers. PLOS ONE. https://doi.org/10.1371/journal.pone.0223378 (2019).

23. R: A Language and Environment for Statistical Computer, R Core Team, R Foundation for Statistical Computing, Vienna, Austria, Version 3.6.3 "Holding the Windsock (2020). https://www.R-project.org. Accessed (2019)

24. Clinical Laboratory Standards Institute, CLSI. Performance Standards for Antimicrobial Disk and Dilution Susceptibility Tests for Bacteria Isolated from Animals; Approved Standard 4th edn. (Clinical Laboratory Standards Institute, CLSI, 2018).

25. Seekatz, A. M. et al. Fecal microbiota transplantation eliminates clostridium difficile in a murine model of relapsing disease. Infect. Immun. 83, 3838-3846. https://doi.org/10.1128/IAI.00459-15 (2015).

26. Kozich, J. J., Westcott, S. L., Baxter, N. T., Highlander, S. K. \& Schloss, P. D. Development of a dualindex sequencing strategy and curation pipeline for analyzing amplicon sequence data on the MiSeq Illumina sequencing platform. Appl. Environ. Microbiol. 79, 5112-5120. https://doi.org/10.1128/AEM.01043-13 (2013).

27. Callahan, B. J. et al. DADA2: High-resolution sample inference from illumina amplicon data. Nat. Methods 13, 581-583. https:// doi.org/10.1038/nmeth.3869 (2016).

28. Callahan, B. J., McMurdie, P. J. \& Holmes, S. P. Exact sequence variants should replace operational taxonomic units in marker-gene data analysis. ISME J. 11, 2639-2643. https://doi.org/10.1038/ismej.2017.119 (2017)

\section{Acknowledgements}

The authors would like to acknowledge the assistance of The University of Michigan Microbial Systems Molecular Biology Laboratory. The authors would also like to thank James Robertson for his assistance with the statistical analysis.

\section{Author contributions}

M.J., M.P. and D.F. contributed to the study design, data collection and analysis and manuscript preparation. H.S., B.C., T.P. and J.H. contributed to data collection and analysis and manuscript preparation.

\section{Competing interests}

The authors declare no competing interests.

\section{Additional information}

Supplementary Information The online version contains supplementary material available at https://doi.org/ 10.1038/s41598-021-90647-z.

Correspondence and requests for materials should be addressed to J.L.H.

Reprints and permissions information is available at www.nature.com/reprints.

Publisher's note Springer Nature remains neutral with regard to jurisdictional claims in published maps and institutional affiliations.

Open Access This article is licensed under a Creative Commons Attribution 4.0 International License, which permits use, sharing, adaptation, distribution and reproduction in any medium or format, as long as you give appropriate credit to the original author(s) and the source, provide a link to the Creative Commons licence, and indicate if changes were made. The images or other third party material in this article are included in the article's Creative Commons licence, unless indicated otherwise in a credit line to the material. If material is not included in the article's Creative Commons licence and your intended use is not permitted by statutory regulation or exceeds the permitted use, you will need to obtain permission directly from the copyright holder. To view a copy of this licence, visit http://creativecommons.org/licenses/by/4.0/.

(C) The Author(s) 2021 